\title{
Contemporary Method to Study Humanities and Social Sciences
}

\author{
Kasomo Daniel \\ Maseno University in Kenya Department of Philosophy Religion and Theology
}

\begin{abstract}
Critical discourse analysis (CDA) is a contemporary approach to the study of philosophy, language and discourses in social institutions. Being a multidisciplinary approach and drawing from poststructuralist discourse theory, critical theory, critical linguistics, semiotics and social psychology among many approaches, it focuses on how social relations, identity, knowledge and power are constructed through written and spoken texts in social institutions like communities, schools and classrooms. This paper describes the historical contexts and theoretical precedents for sociological models for the study of language, Philosophy discourse and text in discourse communities and generally social science research and suggests the path research would follow using a discourse analysis approach. These should be useful resource with implications for higher education.
\end{abstract}

Keywords Analysis, Critical, Discourse, Humanities, Science, Social

\section{Introduction}

Life is in many ways a series of conversations and that talking is 'something we tend to take for granted'. When linguists and other social scientists analyse discourse, their aim is to make explicit what normally gets taken for granted; it is also to show what talking accomplishes in people's lives and in society at large(Cameroon 2001:7)

In most cases, when thinking about discourse, we think the spoken word. However, discourse analysis may however not deal only with spoken discourse, but also with written data, data from sign language, textual graphics as well as images (Kress and Van Leeuwen, 1996; 2001). Basically, there are two distinctions that ought to be made clear. Some discourse analysts, who are in most cases linguists, analyse discourse as an end in itself, i.e. they are primarily concerned to describe the complex structures and mechanism of society situated language use. These analysts will look at issues like Turn-taking in conversations, Topic management, Interruptions and Question raising, etc. These researchers are primarily concerned to describe the complex structures and mechanisms of socially situated language-use. They study talk because they want to know more about Talk.

However, some linguists, and many researchers who are not necessarily linguists are more interested in the idea that 'life is in many ways a series of conversations'. In this case then, people's talk can be a source of evidence about other

* Corresponding author:

dkasomocounselling@yahoo.com (Kasomo Daniel)

Published online at http://journal.sapub.org/ijpbs

Copyright (C) 2011 Scientific \& Academic Publishing. All Rights Reserved aspects of their talk. And though they may not be studying discourse as an end in itself, many sociologists and social psychologists or researchers in education, in cultural studies and media studies, adopt methods which produce discourse data(Cameroon, 2001:8). Interviews, focus group discussions and ethnographic studies using participant observation all involve verbal interaction between researcher and research subjects themselves. At least some of the analysis carried out by researchers who choose these methods will involve listening to talk, transcribing it and reflecting on its meaning and significance. It is from this basis, that Discourse analysis is therefore seen as a useful resource in research in both the social sciences and humanities.

\subsection{What really is (Critical) Discourse Analysis}

It is difficult to give a single definition of(Critical) Discourse Analysis as a research method. Indeed, rather than providing a particular method, Discourse Analysis can be characterized as a way of approaching and thinking about a problem. In this sense, Discourse Analysis is neither a qualitative nor a quantitative research method, but a manner of questioning the basic assumptions of quantitative and qualitative research methods. Discourse Analysis does not provide a tangible answer to problems based on scientific research, but it enables access to the ontological and epistemological assumptions behind a project, a statement, or a method of research. Discourse Analysis will therefore enable to reveal the hidden motivations behind a text or behind the choice of a particular method of research to interpret that text. We can thus see Critical Discourse Analysis is a deconstructive reading and interpretation of a problem or text. Discourse Analysis will however not provide absolute an- 
swers to a specific problem, but enable us to understand the conditions behind a specific 'problem' and make us realize that the essence of that 'problem', and its resolution, lie in its assumptions; the very assumptions that enable the existence of that 'problem'. By enabling us to make these assumptions explicit, Discourse Analysis aims at allowing us to view the 'problem' from a higher stance and to gain a comprehensive view of the 'problem' and ourselves in relation to that 'problem'. Discourse Analysis is meant to provide a higher awareness of the hidden motivations in others and ourselves and, therefore, enable us to solve concrete problems - not by providing unequivocal answers, but by making us ask ontological and epistemological questions.

Discourse Analysis is generally perceived as the product of the post-modern period. The reason for this is that while other periods or philosophies are generally characterized by a belief-system or meaningful interpretation of the world, post-modern theories do not provide a particular view of the world, other that there is no one true view or interpretation of the world. Post-modern theories, therefore, offer numerous readings aiming at 'deconstructing' concepts, belief-systems, or generally held social values and assumptions. This is also the position of CDA.

The term 'critical' is understood very differently and has also been misunderstood widely(see Widdowson, 1998). 'Critical' does not mean detecting only the negative sides of social(inter)action and processes and painting a black and white picture of societies. Quite to the contrary, 'critical' means distinguishing complexity and denying easy dichotomous explanations. It means making contradictions transparent. Moreover, 'critical' means self-reflection while doing research and focusing on relevant social problems. Self-reflection by the researchers is an especially important factor(Wodak and Ludwig 1999; 12). Basically then, 'critical' is to be understood as having distance to the data, embedding the data in the social, taking a political stance explicitly, and a focus on self- reflection as scholars doing research. For all those concerned with Critical Discourse Analysis(CDA), application of the results is important, be it practical seminars for teachers, doctors and civil servants or on writing expert opinions or devising school books(Wodak, 2001). CDA is 'Critical' in two senses. One sense is based on the ideas of the Frankfurt school (Habermas, 1973), and the other on a shared tradition with Critical Linguistics. According to Habermas(1994), a critical science has to be self reflective; it must reflect the interests on which it is based, and it must also take account of the historical contexts of interactions(Habermas 1973, 1977; quoted in Wodak et al 2000; 144). To Habermas, through rational discourse, ideologically impaired discourse may be overcome, and an approximation to the ideal speech situation may be achieved.

Critical discourse analysis refers to the use of an ensemble of techniques for the study of textual practice and language use as social and cultural practices(Fairclough, 1992). Critical discourse analysis begins from the assumption that systematic asymmetries of power and resources between speakers and listeners, readers and writers can be linked to their unequal access to linguistic and social resources. In this way, the presupposition of critical discourse analysis is that institutions like schools act as gatekeepers of mastery of discursive resources: the discourses, texts, genres, lexical and grammatical structures of everyday language use. What this suggests is a reframing of questions about educational equality in terms of how systematically distorted and ideological communication may set the conditions for differential institutional access to discursive resources, which are the very educational competences needed for social and economic relations in information-based economies.

Discourse and language in everyday life may function ideologically. They may be used to make asymmetrical relations of power and particular textual portrayals of social and biological worlds appear 'a given, commonsensical and 'natural'(what Lukács, 1971 and Giddens, 1979 call reification). Accordingly, the task of critical discourse analysis is both deconstructive and constructive. In its deconstructive moment, it aims to disrupt and render problematic the themes and power relations of everyday talk and writing. In its constructive moment, it has been applied to the development of critical literacy curriculum that aims towards an expansion of students' capacities to critique and analyse discourse and social relations, and towards a more equitable distribution of discourse resources(Fairclough 1992).

The principal unit of analysis for critical discourse analysis is the text or discursive units, which is the concrete representation of discourse. Texts are taken to be social actions, meaningful and coherent instances of spoken and written language use. Yet their shape and form is not random or arbitrary. Specific text types or 'genres' serve conventional social uses and functions. That is, particular kinds of texts attempt to 'do things' in social institutions with predictable ideational and material effects. These include functional written texts(e.g., news information, business letters, forms, policies, company statements and reports, academic papers, textbooks), spoken face-to-face interactions(e.g., clinical exchanges, service exchanges, classroom lessons, pictures, symbols, artefacts, transcripts of social interactions such as conversations, focus group discussions, and individual interviews), and multimodal visual, electronic texts(e.g., internet home pages, TV programs, advertisements, magazines, novels).

Texts are almost irrelevant if taken individually. It is only their interconnection that makes discourse analysis valuable. Discursive activity doesn't occur in a vacuum, and discourse in itself doesn't hold a meaning. Accordingly, if we are to understand discourse, we must also understand the context, in which they arise(Van Dijk 1997, Titscher et al 2000, Wodak, 2000), whether broad or local(Cicourel 1992), or what Schegloff(1992) refers to as distal and proximate context. Wodak(1996: 21) perceives context in terms of concentric circles and gives this as follows;

The smallest circle is the discourse unit itself, and this forms up the microanalysis of the text. 
The next circle consists of the speakers and audience; of the interactants with their various personality features, biographies and social roles.

The third context level involves the 'objective setting'; the location in time and space, and the description of the situation.

The fourth circle signifies the institution in which the event takes place.

The fifth circle could naturally expand to the society in which this institution is integrated; its function in society, and its history.

Wodak makes an emphasis of intertextuality and its importance at all these levels. The integration of all these context levels, she adds, would then lead to an analysis of discourse as social practice. Exploration of the interplay between discourse, text, and context therefore builds the focus of the discourse analysis. We must consequently observe selections of the texts that embody discourses. We would not concentrate on an individual text but on a set of them. However, we must refer to the concrete bodies of the texts. Similarly, we should examine the context in which the texts were found and discourses were produced.

\section{Conceptual and Theoretical Frame- works}

Since CDA is not a specific direction of research, it does not have a unitary theoretical framework. With the aims of discourse being varied, there are many types of CDA(Wodak; Chilton; Fairclough 1989, 1992; Van Dijk), and these may be theoretically and analytically quite diverse. For instance, critical analysis of conversation is very different from an analysis of news reports in the press or of lessons and teaching at school. Yet, given the common perspective and the general aims of CDA, we may also find overall conceptual and theoretical frameworks that are closely related. As suggested, most kinds of CDA will ask questions about the way specific discourse structures are deployed in the reproduction of social dominance, whether they are part of a conversation or a news report or other genres and contexts. Thus, the typical vocabulary of many scholars in CDA will feature such notions as 'power', 'dominance', 'hegemony', 'ideology', 'class', 'gender', 'race', 'discrimination', 'interests', 'reproduction', 'institutions', 'social structure' or 'social order', besides the more familiar discourse analytical notions.

CDA research will often refer to the leading social philosophers and social scientists of our time when theorizing these and other fundamental notions. Thus, reference to the leading scholars of the Frankfurt school and to the contemporary work by Habermas(1989), for instance on legitimation and his last 'discourse' approach to norms and democracy, is of course common in critical analysis. Similarly, many critical studies will refer to Foucault(1980) when dealing with notions such as power, domination and discipline or the more philosophical notion of 'orders of dis- course'. More recently, the many studies on language, culture and society by Bourdieu have become increasingly influential, for instance his notion of 'habitus' in social theory. From another sociological perspective, Giddens(1984) on structuration theory is now occasionally mentioned. These influences also show that one main tradition of critical studies, the neo-marxist one, as for instance inspired by Gramsci(1971) on hegemony.

It builds from three broad theoretical orientations. First, it draws from post structuralism the view that discourse operates laterally across local institutional sites, and that texts have a constructive function in forming up and shaping human identities and actions. Second, it draws from Bourdieu's sociology the assumption that actual textual practices and interactions with texts become 'embodied' forms of 'cultural capital' with exchange value in particular social fields. Third, it draws from neomarxist cultural theory the assumption that these discourses are produced and used within political economies, and that they thus produce and articulate broader ideological interests, social formations and movements within those fields(see Hall 1996).

Drawing from poststructuralist and post-modern discourse theory, which examine how writing, texts and discourses are constructive phenomena, shaping the identities and practices of human subjects, Foucault and Derrida assert that language and discourse are not transparent or neutral means for describing or analysing the social and biological world. Rather they effectively construct, regulate and control knowledge, social relations and institutions, and indeed, such analytic and exegetic practices as scholarship and research. By this account, nothing is outside of or prior to its manifestation in discourse. Foucault does not limit his notion of discourse to language, but refers more generally to reiterated key words and statements that recur in local texts of all kinds. Such statements appear intertextually across texts and comprise familiar patterns of disciplinary and paradigmatic knowledge and practice. By this account, social institutions such as schools and universities are comprised by and through discourses. Discourses make up a dense fabric of spoken, written and symbolic texts of institutional bureaucracies(e.g., policies, curriculum documents, forms) and their ubiquitous face-to-face encounters(e.g., classroom interaction, informal talk). Within these institutions, human subjects are defined and constructed both in generic categories(e.g., as 'children' and 'teachers') and in more specialised and purposive historical categories(e.g., as 'professionals', 'adolescents', 'linguistic deficit', 'preoperational'). These discourse constructions act both as institutional 'technologies of power', implemented and enforced by official authorisation, and they act as 'technologies of the self'(Foucault 1980), internalised means for the self-discipline of action, practice and identity. According to Foucault, these technologies potentially have both productive and negative material, bodily and spatial consequences for human subjects and communities.

Poststructuralist work thus forms a critique of ontology and epistemology in empirical approaches to social science. It makes the case that:(a) all inquiry is by definition a form of 
discourse analysis; and(b) all research consists of a 'reading' and 'rewriting' of a series of texts from a particular historical and epistemological standpoint. In so doing, it provides a radically different perspective on students and teachers, policy and curriculum, schools and classrooms. If we accept its premises, then an appropriate focus of sociological studies would be on how the texts of schooling construct such taken for granted phenomena as individuals, skills, knowledge and institutions. At the same time, it raises significant methodological questions about the status of data and the epistemological standpoint of the educational researcher. Given the primacy of discourse, the social facts studied by sociologists are constructed artefacts of researchers' own discourses and 'namings', and any data collected in the field needs to be treated as a 'readable' text, subject to interpretation.

The insight of philosophic post structuralism, then, is that there is no educational truth, practice or phenomena that can be studied outside of discourse. By such an account, educational institutions could be seen as complex sites constructed by and through discourses expressed in various texts: from policy statements and textbooks to face-to-face talk in classrooms. These texts are seen as 'heteroglossic' articulations of various historical, class and cultural interests contending for social power and capital. The question of how to collect, read and interpret these texts and how to analyse and situate their 'symbolic power' is complex. It requires the study of the diverse 'linguistic markets' and 'social fields' where educationally acquired competence is used(Bourdieu, 1992: 51-65).

As theory and a method, discourse analysis starts from the fundamental assumptions derived from the hermeneutics that language is a medium oriented towards action and function, that people use language intentionally to construct accounts, or versions, of the social world(Elliot, 1996) and that one-to-one correspondence exists between a word(encoding of information) and its meaning(decoding of information) (Zajacova, 2002). Hermeneutics can be understood as the method of grasping and producing meaning relations. The hermeneutic circle implies that the meaning of one part can only be understood in the context of the whole, but that this is in turn only accessible from its component parts(Wodak and Meyer 2001: 16). The main issue of hermeneutics is that the true interpretation has simply not yet been found, but also that there is no such final interpretation.

Given such diversity in discourse analysis, what then is the quality criterion for such an analysis? Firstly, discourse analysis must be intelligible in its interpretations and explanations(Titscher et al 2000: 164) that means trustworthiness of the study. The process of collecting, analysing, and explaining the data must be recognisable. Van Dijk suggests accessibility as a criterion of the quality: findings should be at least accessible and readable for the social group under investigation; what Lincoln and Guba(1985) call 'member check' for qualitative studies. Triangulation techniques are also used to enrich trustworthiness by employing a variety of background information, empirical data, and analysing techniques(Wodak, 2001). Very specifically for discourse analysis is that the value of findings and conclusions is anchored in the inter-subjective validity that means the endless openness and interchange between different types of data, participants' and researcher's interventions, interpretations and explanations, and diverse levels of analysis(individual vs. combination of texts, linguistic vs. context).

\section{Critical Discourse Analysis as Method and Methodology}

Which methods of data collection and analysis are used and which categories in textual analysis, depends on the object of research. CDA as such is best not regarded as a method or homogenous theory with a set of clear and defined tools, but as a field of study or research programme with diverse approaches(Chilton, 1985; Fairclough and Wodak 1997; Wodak 1996), which share certain broad principles (researching relations between discourse and other social elements; researching social topics with a semiotic point of entry; relating detailed features of texts and interactions to social process, categories, relations etc; working within a critical tradition of social research, etc). Particular approaches to CDA do have general methods, and favour particular methods, but particular methods in a particular project depend on the object of research.

Chouliaraki and Fairclough $(2000 ; 10)$ see CDA as both theory and method; as a method for analysing social practice with particular regard to their discourse moments within the linking of the theoretical and practical concerns and public spheres. In this manner, the ways of analysis 'operationalise' and make practical, the theoretical constructions of discourse in social life. The analysis contributes to the development and elaboration of these theoretical constructions. They therefore insist that it is necessary to avoid both theoreticism (theory for its own sake), and methodologism(seeing method as a theory free means of achieving results).

Chouliaraki and Fairclough also see CDA as bringing a variety of theories into dialogue, especially social theories on the one hand, and linguistic theories on the other hand, so that its theory is a shifting synthesis of other theories, though what it itself theorises in particular is the mediation between the social and the linguistic; 'the order of discourse', the social structure of semiotic hybridity(interdiscursivity).

On data collection, CDA is consistent with various methods like documentation research, building corpora of spoken or media discourse, gathering interview data, ethnographic methods.

In terms of Linguistic analysis of texts, in principle any form of linguistic(sociolinguistic, pragmatic) analysis, as well as forms of textual analysis, developed outside Linguistics(e.g. conversation analysis, forms of analysis, of argumentation) might be drawn upon. CDA can also combine qualitative textual analysis, with quantitative analysis, (using methods in corpus linguistics. In practice then, any 
project will selectively focus on a limited range of forms of analysis, and analytical categories, depending on the project and object(s) of research.

On the analytical categories then, we might have to consider issues such as the social events and representation of the social events, the genre, and intertextuality issues. In cases of deep linguistic enquiry, then we might also need to consider-Semantic/grammatical relations between sentences and clauses: exchanges, speech functions and grammatical mood, discourses, modality, and styles.

\section{Practical Applications of CDA to So- cial Science Research}

Following Potter and Wetherell(1987), ten stages of analysing discourse are proposed as follows;

Decide or develop your research question

What research philosophy underpins your research?

What is your object of study? What theoretical influences are you drawing on? What contribution do you hope to make? What is your research question?

\subsection{Sample Size}

Sample size is not usually a main issue in discourse analysis as the interest is in the variety of ways the language is used(Potter and Wetherell 1987). Large variations in linguistic patterning can emerge from a small number of people. So a larger sample size may just make the analytic task unmanageable rather than adding to the analytic outcomes.

In selecting your sample of data, you should ensure that it flows from what your research object is and how you think it is manifested in the world of language. For example, if you're investigating(say) 'heterosexuality', do you seek out the views of heterosexuals? Or would you get a better fix on it by talking to non-heterosexuals? What's the difference? On selecting the research site, ask if it has characteristics that make it likely to produce interesting results? Are research sites sufficiently similar or different along theoretical dimensions to allow comparative analysis? Is the research site likely to produce 'transparent' findings? Has a good source of discursive data presented itself? Has a crisis occurred that will reveal insight into discursive activity?

\subsection{Collect Record}

You will need fairly accurate records that you can always refer back to. You will therefore have to make use of transcripts, cuttings, letters, diaries, videotapes, and so on.

In collecting data, you should be aware of the different types of text like naturally occurring texts, and interviews. You need to know what texts are the most important in constructing the object of analysis. What texts are produced by the most powerful actors, transmitted through the most effective channels, and interpreted by the most recipients? You need to know which of the above texts are available for analysis. Which of the texts are feasible to analyze? How the sampling of the texts will take place, how you will explain the choices you have made

\subsection{Interviews}

These are good because they give you insight into the whole issue. At the same time, the same questions can be asked to many people thus allowing for comparison. But, of course, this introduces the Researcher as a potentially disturbing or intrusive presence into the data - a significant problem, as psychologists well know. Potter and Wetherell are alive to this, but it is not always the case that they remember that their respondents were answering interviewers' questions. It is worth saying that Potter has become much more cautious about interviews, and now takes a position which is much closer to CA: that it is better to analyse more 'naturally-occurring' talk. As Potter(1996, p. 134) has noted, 'interviews have been used extensively in discourse analysis, but they are constructed in a novel manner'. Traditional interviews used to aim at producing colourless interaction. However, in practice, interviews are as complex as any other social events, and responses to answers are dependent on the sculpture of questions and atmosphere during the conversation. You can therefore have the traditional type of interview as well as a discourse oriented type of interview.

The main switch in conducting interviews for discourse analysis is in their rationale. The goal becomes more complex; this is obtaining both consistency and diversity, while in traditional interviews consistency is the main evidence factor. The researcher gets a role of an active participant in the conversation instead of being a 'speaking questionnaire' (Potter and Wetherell 1987). Therefore the techniques used are different, they all strive at getting diversity in opinions and stimulating discussions.

\subsection{Transcriptions}

Transcriptions depend on the goals of your enquiry. There is no single best method of transcription. There is a certain variety in transcribing discourse from work attesting to the phonetic and intonational features. Different transcription systems emphasise different features of interaction. Doing discourse analysis, for example, a sociolinguist concerned with language variety will need an indication of accents; while a researcher interested in speech therapy will be interested in phonetics. Potter(1996: 136) indicates that a ratio of one hour of tape to 20 hours of transcription time reasonable. Yieke(2002) in her work found that one minute of Talk took her between twenty minutes to sixty minutes in terms of the transcription process. Transcription is therefore one difficult and arduous task. This should not however, be seen as a dead time before a 'real' analysis. Often the enlightening analytical insights come during transcribing.

\subsection{Coding}

Do a first pass through the data and keep your eye out for anything that looks interesting(like Gilbert and Mulkay did and noticed 'error' talk). But these 'codings' are only provisional, and always qualitative. No discourse analyst would 
code their material for the sake of counting them up in a quantitative analysis.

\subsection{Analysis}

How does one analyse that data one has? What sort of data does on have? Is it micro or micro or macro? What sort of categories do these data generate? Do these categories relate to the research question? Can the researcher explain and justify his/her choice of categories? How will the researcher know when to stop? This is the crux of it all, of course, and it is here that Potter and Wetherell admit that there is no standard method - no 'recipe'. Rather, there are a few rules of thumb: "Why am I reading the passage this way? What features produce this reading?. Ignore nothing; anything may turn out to be significant. Specifically, look for variability and consistency in what is said(and perhaps what is not said). How will I analyze my data?

After the first stage of analysis, go through all the data again, checking the appearance of any 'repertoires' or 'discourses' that you have started to find. "It should be clear, then, that there is no analytic method, at least as understood in social psychology. Rather, there is a broad theoretical framework, which focuses attention on the constructive and functional dimensions of discourse, coupled with the reader's skill in identifying patterns of consistency and variation" (Potter and Wetherell, 1987: 169).

\subsection{Validation}

Look for;

How the discourses you have identified helps understand the coherence of the data

How the participants themselves orient to the discourses (that will remind you of 'participants orientation' in Conversation Analysis

New problems - what is still unexplained

\subsection{Write up}

Be frank about what your argument is and how the data are to be interpreted. Although those steps from Potter and Wetherell's 1987 book, which is now sixteen years old, they are still useful as a way of describing the general 'method'. Where things have changed is in step 6 and 7 . There is now a great variety of what counts as coding and analysis. This has led to a recent debate about methods.

What is the research question?

Why did I choose the research site?

What data did I collect and why?

How did I analyze the data?

How does the analysis address the research questions?

What contributions does this research make?

\section{Educational Implications of a Dis- course Analysis}

The principal focus of discourse analysis in education in the 1970s and 1980s was on instances of face-to-face talk between, for instance, care-givers and children as key moments in language socialisation, and the development of literate competence and cultural identity(Cazden, 1988). Application of ethnomethodological approaches to the study of classroom talk(Mehan 1979) and to educational texts (Baker and Freebody 1989) further showed how normative categories of gender, student disability, deficit and disadvantage were constructed in the exchange structures and themes of classroom talk.

Discourse analysis could also provide a framework for describing how educational texts construct children, teachers, students and human subjects in different relations of power and knowledge. The development of discourse analysis of educational texts thus mirrors some of the unresolved theoretical dilemmas in sociology of education and in the emergence and application of cultural studies to education. While sociolinguistic work has stressed microanalyses of face-to-face language use in classrooms, textbooks and student texts, genealogical studies of curriculum and policy have tended to provide broad interpretive analyses of the historical development of institutional and knowledge structures with less detailed textual analysis. By contrast, much feminist and postcolonial writing has focused on the production of situated accounts of experience and identity formation, marginality and exclusion. The outstanding task for critical discourse analysis, then, is to provide detailed analysis of cultural voices and texts in local educational sites, while attempting to theoretically and empirically connect these with an understanding of power and ideology in broader social formations and configurations. Within the fields of 'critical pedagogy' and 'feminist pedagogy' then, a $\mathrm{CDA}$ is seen to serve educative and emancipatory political projects.

Gender studies can be carried out within a CDA perspective. Research on gender, language and discourse could for instance look at issues of social inequality, female resistance and(male) domination like; Power differences in everyday conversational interaction; Verbal sexual harassment; Gender inequalities in bureaucratic and professional text and talk; Limited access to and control over various forms of media discourse; Discrimination in hiring and glass ceilings in promotion in discourse producing organizations, such as the media and publishing industries; Stereotypical and sexist representations of women in male-dominated discourse in general, and in the mass media in particular. All these issues are gender issues that are still pervasive and could be tackled within a CDA agenda. However, despite significant changes in the position of women over the last decades, and despite many forms of successful oppositional and dissident discourse, most of these forms of discursive gender domination and inequality persist until today, although sometimes in more indirect and subtle manifestations.

The study of the role of discourse in the enactment and reproduction of ethnic and racial inequality has also slowly emerged in CDA. Traditionally, such work focused on eth- 
nocentric and racist representations in the mass media, literature and film(Van Dijk, 1991). We take up this strand, and within our context, think of issues of nationalism, tribalism, and ethnicity, which are pervasive in our institutions. Using CDA, we are able to handle cases of marginality and marginalization, the ever pervasive 'Us' versus 'Them' or the 'Other'. An interesting result of most of these studies is the remarkable similarity between the stereotypes, prejudices and other forms of verbal derogation, across discourse types, media, and national boundaries. Essentially, what we find is that the 'Others' are predominantly represented in terms of(a) socio-cultural differences,(b) deviation from dominant norms and values, and(c) violence and threat. Thus, cultural differences will be enhanced and magnified and similarities ignored or mitigated. Besides such consistent negative 'Other' presentation, the in-group is positively represented along these and other dimensions of relevant comparison.

\section{Conclusions}

Critical discourse analysis provides an interdisciplinary analytic approach and a flexible meta-language for the sociological analysis of texts and discourses. The emergence of critical discourse analysis has at least three interrelated implications for educational studies and research.

Firstly, it marks out a re-theorisation of educational practice. The metaphor offered by post-structuralism is that of the text as an interpretable phenomena that is constitutive of all educational and intellectual endeavour.

Secondly, Critical Discourse Analysis marks out a new set of methodological techniques and possibilities. The assumption shared by many quantitative and qualitative approaches to sociological research has been that observable realities, truths and social facts have an essential existence prior to discourse. Critical discourse analysis begins from a recognition of language and discourse as non-transparent, opaque ways of studying and representing the world. It recasts all data and research artefacts as discourse. It raises and addresses the question of self-reflexivity by making researchers' own uses of discourse a key problematic in design and inquiry.

Finally, Critical Discourse Analysis marks out the grounds for rethinking pedagogical practices and outcomes as discourse. The assumption underlying many curriculum development and instructional models is that the purpose of education is to produce behaviours, skills and competences required for modern day workplaces and civic spheres. CDA suggests that mastery of discourse is the principle educational process and outcome, and that this mastery can be normatively reshaped to introduce teachers and students to critical analyses of text-based, post-modern cultures and economies. A turn to the study of languages, discourses and texts will be needed if indeed we are to understand how educational institutions might make a difference in post-modern economies, nation states and cultures.

\section{REFERENCES}

[1] Baker, and Freebody., 1989, Bourdieu, P.,1992, Language and Symbolic Power, Polity Press, Cambridge

[2] Cameron, D.,2001, Working With Spoken Discourse. London: Sage publications Ltd

[3] Cazden,, 1988, Chilton, P., 1985, Chouliaraki, L. and N. Fairclough, 1999, Discourse in Late Modernity. Edinburgh: Edinburgh University Press

[4] Cicourel, A.,1992, 'The Interpretation of Communicative Contexts: Examples From Medical encounters'. In Duranti and Goodwin(ed.) Rethinking Context: Language as an Interactive Phenomenon. Cambridge: CUP(291-310)

[5] DerridaElliot, R.., 1996, 'Discourse Analysis: Exploring Action, Function and Conflict in Social Texts'. Marketing Intelligence and Planning, 14(6), $65-68$

[6] Hall S.,1996, 'The Meaning of New Times'. In Morley D, Chen K(eds) Stuart Hall: Critical Dialogues in Cultural Studies. London: Routledge

[7] Fairclough, N.,1995, Critical Discourse Analysis. London: Longman

[8] Fairclough N.,1992, Discourse and Social Change. Cambridge: Polity Press

[9] Fairclough, N.,1989, Language and Power. London: Longman

[10] Foucault, M.,1980, Power/Knowledge(trans. C. Gordon). New York: Pantheon

[11] Giddens, A.,1984, The Constitution of Society: Outline of the Theory of Structuration. Cambridge, England: Polity press

[12] Giddens, A.,1979, Central Problems in Social Theory. Berkley: University of California

[13] Gramsci, A.,1971, Selections From the Prison Note Books (trans. Q. Hoare \& G. Nowell Smith). New York: International Publishers

[14] Habermas, J., 1994, 'Ideology'. In Eagleton, from Rottomore, T. (ed.) Interpretations of $\operatorname{Marx}(1988)$. Oxford: Basil Blackwell. 190-201

[15] Habermas J.,1989, Theory of Communicative Action. Lifeworld And System: A Critique of Functionalist Reason. Vol. 2: (Trans. Thomas Mc Carthy). Boston, MA: Beacon

[16] Habermas, J.,1973, Theory and Practice. (Transl.J.Viertel). Boston: Beacon Press

[17] Kress, G. and T. Van Leeuwen.,2001, Multimodal Discourse: The Modes and Media of Contemporary Communication. London: Arnold publishers

[18] Kress, G. and T. Van Leeuwen.,1996, Reading Images: The Grammar of Visual Design. London: Routledge Lincoln and Guba

[19] Luke, A., 1995, Text and discourse analysis in education: An introduction to critical discourse analysis. Rev.Res.Ed. 21:1-48 
[20] Luke, Allan., 2000, 'Introduction: Theory and Practice in Critical Discourse Analysis', in L. Saha(ed) International Encyclopedia of the Sociology of Education, Elsevier Science Ltd. Contract No: 20702A008. Article No. 504057

[21] Lukács, George., 1971, History and Class Consciousness. Cambridge: MIT Press

[22] Potter, J.,1996, 'Discourse Analysis and Constructionist Approaches: Theoretical Background'. In: J.Richardson (eds.), Qualitative Research Methods for Psychology and Social Sciences,Leicester: British Psychological Society. 125 $-140$

[23] Potter, J. and M. Wetherell.,1987, Discourse Analysis and Social Psychology. London: Sage

[24] Schegloff, E.,1992, 'On Talk and its Institutional Occasions'. In P. Drew and J. Heritage(ed.) Talk at Work: Interaction in Institutional Settings. Cambridge: Cambridge University Press. $101-136$

[25] Titscher, S., M. Meyer, R. Wodak and E. Vetter., 2000, Methods of Text and Discourse Analysis. London: Sage Publication

[26] Van Dijk, T.A.,1997, Discourse as Structure and Process:
Volume 1 and 2. London: Sage

[27] Widdowson, H.,1998, 'The Theory and Practice of Critical Discourse Analysis Review Article'. Applied Linguistics 19/1: 136-151

[28] Wodak, R.,1996, Disorders of Discourse. London: Longman

[29] Wodak, R.,2001, 'What CDA is About - A Summary of its History, Important Concepts and its Developments'. In R. Wodak and M. Meyer(eds.) Methods of Critical Discourse Analysis. London: Sage Publications

[30] Wodak, R. and M. Meyer., 2001, (ed.) Methods of Critical Discourse Analysis. London, New Delhi: Sage

[31] Wodak, R. and C. Ludwig., 1999, (ed.) Challenges In A Changing World. Issues in Critical Discourse Analysis. Wien: Passagen

[32] Yieke, F.,2002, Language and Discrimination: A Study of Gender and Discourse in Workplaces in Kenya. Unpublished $\mathrm{PhD}$ Thesis. University of Vienna, Austria

[33] Zajacova, A.,2002, 'The Background of Discourse Analysis: A New Paradigm in Social Psychology'. Journal of Social Distress and the Homeless, 11(1), $25-40$ 